\title{
EL LENGUAJE DE LA GEOGRAFÍA Y EL LENGUAJE DE LOS GEÓGRAFOS
}

\author{
Jesús García Fernández \\ Universidad de Valladolid
}

\begin{abstract}
RESUMEN
En los últimos años, menudean expresiones y términos en el lenguaje de los geógrafos que poco tienen que ver con la geografía. Por lo general se trata de términos aprehendidos de otras disciplinas, como la geología o la arquitectura, pero cuya aplicación en geografía resulta forzada, cuando no equívoca. Este artículo pretende exponer algunos de los casos más llamativos, y contribuir a una reflexión científica sobre la necesidad de cuidar el lenguaje que nos sirve para comunicar la geografía.
\end{abstract} bulario.

Palabras clave: lenguaje de los geógrafos, expresiones, términos, geografía, voca-

\begin{abstract}
In recent years, expressions and terms in geographers languaje are frequently repeated, but not involved with Geography. Generally it is about apprehended terms of other disciplines like Geology or Architecture, but whose application in Geography is forced, if not ambiguous. This paper tries to expose some of showiest cases and to contribute to a scientific reflection on the necessity to take care of the language that serves us to communicate geography.
\end{abstract}

Key words: geographer's languaje, expressions, terms, geography, vocabulary.

Todas las ciencias y modos de conocimiento, para expresar sus conceptos básicos han tenido que recurrir a un lenguaje propio. En unos casos ha sido a palabras griegas o latinas para darles un significado específico; en otros son términos o vocablos del propio idioma, que han sido singularizados. Unas veces son algo exclusivo de los especialistas, pero otras muchas han pasado al acervo de las personas cultas, que las entienden en este sentido e incluso las emplean de modo cabal; sin que falten también los que las utilizan de manera 
más imprecisa, cuando no errónea. Son palabras que se han incorporado al lenguaje convencional con sanción oficial o de modo oficioso.

Así cada ciencia o modo de conocimiento tiene su propio lenguaje, aunque es frecuente que derive en una verdadera jerga, que sólo es asequible a sus cultores. Es el lenguaje logogrífico para los profanos. No obstante muchos de estos términos han sido difundidos y forman parte del lenguaje general. Otra cuestión es que sean empleados con la debida corrección. Para unos y para otros son al expresión más paladina de lo científico.

La geografía como modo de conocimiento de la complejidad de la superficie terrestre también tiene su propio lenguaje, y muy numeroso. Siempre ha adoptado para expresar los hechos que tienen carácter de generalidad, términos creados por ciencias con las que tiene afinidad, aunque su objeto sea muy distinto; y muy frecuentemente, poco avinentes con lo que es geográfico en cuanto tal. Pero también ha acuñado palabras que son más exclusivas de ella. En unos casos a partir de vocablos locales, e incluso del «sermo rusticus». Pero al ser las primeras para denominar un hecho han tenido fortuna, y han adquirido carácter de generalidad. Igualmente a determinadas palabras del lenguaje convencional les ha dado un significado particular.

Sin embargo, por un prurito científico, condigno con el cientifismo en boga, desde hace ya más de medio siglo la creación de neologismos, muy frecuentemente inanes, ha aumentado como un gallarín. El paso de la geografía de la Europa continental a la del mundo anglosajón ha sido la multiplicación de los panes y de los peces, y no siempre con mesura.

En España por el tardío desarrollo de la geografía a partir de los años cincuenta del siglo $\mathrm{XX}$, pese a que haya quien en una «etapa naturalista» pretenda remontarla al último tercio del siglo anterior, lo que ha dominado es la traducción de términos extranjeros; primero de la geografía francesa y pocos de la alemana; decenios después, y cada vez más, se ha pescado en el cardumen variopinto anglosajón. Ciertamente muchas de esas palabras expresan verdaderos conceptos, aunque haya otras, y no siempre, que son más expresivas en español. Sería absurdo desechar aquéllas, dado el carácter universal que han adquirido. Pero son muchas más, al igual que otras que enhebran el discurso, que resultan un contrasentido, son dilusorias, y hasta grotescas. Todo da la impresión en muchos papers, que no pasan de papeles, de que en vez de poner el inglés en español, trasmutan éste en inglés. Hay artículos, e incluso libros, en que estos voquibles aparecen adunia. Así hay párrafos que resultan ininteligibles. Son algo caliginoso, en los que se requiere un esfuerzo mental para entenderlos. Se acaba por pensar si es que algunos autores saben realmente lo que escriben. Y esto se agrava, cuando de lo escrito se pasa al discurso oral. Entonces es una verdadera logomaquia.

Tales modos, más bien malos modos, se han acrecentado con el tiempo. El complejo de inferioridad de los geógrafos españoles les ha llevado a buscar inspiración desde hace ya décadas en los anglosajones, y con frecuencia en libros que incluso se alejan de la geografía. Hay una verdadera obsesión por estar al día, que en los currutacos de varias generaciones es lo que lleva rodando, y hasta ha quedado periclitado, hace diez o quince años. Es la novedad de los «geógrafos a la violeta». Así hay artículo sobre cuestiones muy concretas de España, cuya bibliografía está repleta de trabajos anglosajones, sin que se advierta relación alguna con el tema tratado. Se puede parodiar en estos casos aquellos versos de Cadalso: «geógrafos que tal vez citarían cien mil autores anglosajones / puede ser que no sepan / lo que han escrito sus colegas españoles». Esto se llama pedantería. Pero como se lee, si es que se hace, deprisa, y no siempre conociendo el idioma propio, se eligen palabras nuevas sin meditar su significado, que tienen un sentido muy distinto. Hay de este modo verdaderos coprógrafos, que machacan el español a golpes de neologismos chirles.

Pero de la pedantería se pasa con frecuencia a la petulancia. Por el modo y la aversión a leer con detenimiento, hay conceptos para los cuales se ha acuñado una palabra que oída 
o vista a sobrevienta en los titulares, se les da un significado distinto. ¡Para qué averiguar a qué corresponden! Así hay geógrafos famosos, muy dados a la grafomanía, que los emplean marrando. Les resbala el cerebro en la suerte de varas.

Por último, en esta época de inflación del «pensamiento geográfico», los geógrafos se han hecho muy «librepensadores», en el sentido de que se han librado de pensar; ya otros lo han hecho por ellos (sic.). Así, conceptos que llevan rodando muchos años, y aun sobrepasan el siglo, continúan siendo iterados. Si en su momento fueron poco afortunados por no reflejar la realidad, hoy lo son menos. Se han convertido en tópicos heñidos; algunos de los cuales han adquirido tal difusión que han pasado al lenguaje culto, y hasta vulgar con un significado polisémico. El deber de todo modo de conocimiento es discernir conceptos - palabras - y no confundir con ellas. También ha ocurrido a la inversa. Expresiones o palabras del lenguaje de los medios de comunicación, que no se sabe cómo han aparecido, se han incorporado irreflexiblemente a la geografía. Ni responden a su realidad, ni a su verdadero significado. ¡Toda una paradoja cuando se reitera su carácter científico!.

Por fas o por nefas el lenguaje de la geografía en manos de los geógrafos en muchos casos se ha convertido más que en una jerga, en una jerigonza; unas veces hebén, y otras logogrífica. Y semejante hecho tiene dos consecuencias, cada cual más funesta. Se itera hasta la saciedad que «la geografía es una ciencia social». En caso de serlo, mal puede cumplir su misión, cuando difícilmente por lo obtuso de su lenguaje puede llegar a las gentes cultas de la sociedad, hoy teóricamente mucho más numerosas, que no en un otraño todavía muy cercano. Su proyección social por paradoja, y también por desgracia, es cada vez menor. Pero sobre todo un mal mayor es el desaforado atentado que se está haciendo contra el español. Éste, merece todo el respeto, porque en él se encuentra implícita la prehistoria, la historia y el sentimiento del pueblo español, aparte de otros muchos pueblos, que con muchos millones de habitantes lo hablan y escriben. Es el mayor legado de España, pues como ha escrito Neruda sobre los colonizadores, «nos dejaron todo... nos dejaron las palabras».

Con este escrito mi propósito tiene tanto de admonición, como de una reflexión para los colegas españoles del uso que hacen del lenguaje en la geografía ${ }^{1}$. Sin embargo hacer una clasificación por temas me resulta difícil, porque se mezclan traducciones de palabras extranjeras de modo chanflón - más bien son las vernáculas de otras lenguas puestas en español - y hasta grotesco con tópicos carentes de sentido, cuando no expresiones que carecen de toda racionalidad. Por eso en mi excurso - lo que se sale del curso habitual - me referiré tan sólo a algunas de estas irregularidades de lo correcto por incorrecto de los geógrafos de España.

Primero abordaré expresiones más generales, que tienen un carácter regional con perdón de aquellos para los que este modo de tratar resulta un reniego, ya que para ellos lo «regional» tiene todo lo que no ha sido, y no lo es; pero se empeñan en que lo sea. Desde luego no voy por ahí. Después me ocuparé de algunos conceptos tan manidos como mal empleados, y que son un contrasentido en la geografía. Posteriormente trataré de una serie de vocablos, que iteradamente aparecen en esos que se llaman los «geógrafos humanos» en contraposición a otros, que hay que entender que son los «geógrafos inhumanos», los de la geografía física. En ambos hay para dar y tomar. Por último me consagraré a esos otros términos que enhebran el discurso logomáquico en la multitud de «papers curriculares»,

1 Precisamente por esta finalidad no introduzco las citas bibliográficas correspondientes, ya que no se trata de criticar a nadie; más cuando hay geógrafos que por sus obras merecen todo respeto. Tampoco lo hago para aspectos generales por ser de sobra conocidos; incluso prescindo de las mías en aspectos relacionados con este tema, y de los cuales he tratado en diversos trabajos. 
que anegan nuestras revistas, y que dan carácter científico a lo que muy frecuentemente son meros papasales, si no centones, recogidos de aquí y allá por verdaderos escarabajos peloteros. A la futesa de su contenido se une el de su lenguaje críptico. Es muy fácil pensar mal o hacerlo de prestado, que no el pensar y escribir bien. Menos mal que aún han tenido la sindéresis de no introducir el lenguaje mazorral tan habitual en la prensa cotidiana. ¡Parece que todavía hay clases!

\section{Denominaciones mal empleadas o irracionales}

Quizá entre estas últimas la más incongruente es la de cornisa cantábrica para designar el escalón costero o la faja más próxima al litoral, que desde Galicia se extiende a poniente. Lo mismo desde el punto de vista geográfico que en el del lenguaje, carece de sentido. «Cornisa es aquella parte saliente de un tejado, que en su parte inferior está decorada con molduras». En esto se distingue de «alero» o «socarrén» que igualmente podrían haber sido utilizadas. Cuando lo leo, me viene a las mientes que sus habitantes y todo su entramado geográfico están encima del mar, que penetra por debajo. Por eso más que una expresión irracional, me parece una expresión ridícula. Sin embargo, ha tenido la mala fortuna de ser afortunada; y hasta son muchos los geógrafos que la han adoptado.

Semejante contrasentido no sé de dónde ha salido. Presumo que lo ha acuñado algún ignaro locutor o presentador de los llamados medios de comunicación. Pero el oído de los radioescuchas o los telespectadores es muy prono a semejantes denominaciones. Ni unos ni otros tienen la obligación de pensar, ni tampoco la costumbre de consultar un diccionario. Pero los geógrafos sí, para algo que deben conocer por su oficio. Sobre todo cuando, además, tiene mucho de lábil.

En descarga de ellos está que «cornisa» como sinónimo de fachada también ha sido empleado por algunos arquitectos en los primeros años del régimen surgido de la Guerra Civil, e igualmente bastante después. Se utilizaba cuando, a determinados sectores de una ciudad que no podía ofrecer buenas perspectivas, se le quería dar un porte digno mediante altos y bellos edificios. Naturalmente los arquitectos proyectan, y además con pretensiones artísticas, aunque no siempre; pero algunas de estas dotes parecen no estar avenidas con su cultura. Sin embargo, si un dislate localizado es vitando, todavía lo es más el que se llegue a otro mucho mayor, y sobre todo que se haya incrustado en la geografía.

La denominación de cornisa cantábrica, por tanto, debe de ser desterrada de ella; y ser sustituida por escalón costero o faja litoral o por cualquier otra de más abolorio local.

Otra denominación que tiene tanto de irracional como de irrelevante es la de Cordilleras Béticas. Se trata de uno de esos geologismos incorporados a la geografía, que se siguen repitiendo por inercia y sin ninguna reflexión. Se deriva de los conceptos meramente geológicos penibética, que también comprende otros, subbética y prebética, que nada tienen que ver ni con el relieve, ni aun con las estructuras geológicas, muy variadas de unos sectores a otros. Sin embargo, raro es el geógrafo que ha reaccionado ante una denominación que condice poco con lo que es su verdadera realidad geográfica. Más con los conocimientos que hoy se tienen, no tanto de este gran conjunto montañoso, bastante poco estudiado geográficamente, como generales sobre el relieve. Continúa siendo una sevicia de la geología enteramente fútil. ¿Por qué no se denomina a los Pirineos, como cordilleras pirenaicas? Aunque sean de diferentes características presentan una magnitud y complejidad semejantes, pero se consideraría tal denominación como algo absurdo. De ahí que para la geografía, ni montañas ni cordilleras béticas sea lo apropiado; basta con Cordillera Bética.

Algo análogo ocurre, cuando a la Cordillera Ibérica, e incluso a la Central, se les denomina Sistema Ibérico y Sistema Central. Es algo completamente impropio. Un sistema es 
una construcción humana enteramente. Es un conjunto de hechos que están relacionados dialécticamente de modo coherente. Puede ser algo referente al pensamiento - un sistema filosófico-; o también alto técnico, como un sistema de comunicaciones, o incluso un sistema de alcantarillado. Pero aplicar tal concepto a la corteza terrestre tiene mucho de hipérbole, si no es un desatino. No se puede constatar ni la coherencia, ni el funcionamiento en cuanto a lo que es propiamente un sistema. No se ha pasado del plano de lo teórico, en el que lo verosímil y lo inverosímil se mezclan. Si nos atenemos a su formación en millones de años del pasado geológico es mucho más lo que falta por averiguar, que lo que se puede constatar.

Pero además, esto es lo geológico, que ha sido muy cambiante en el tiempo; y todo lleva a pensar que va a seguir siéndolo. Lo geográfico es la disposición o estructura que presentan estos supuestos sistemas. Es decir, el tipo de relieve o de relieves que presentan. Y para eso es mucho más preciso y expresivo el nombre de cordillera en la acepción que se ha tomado desde los siglos XVI-XVII. Antes, y tradicionalmente, se daba tal denominación a algo de mucha menor escala: era «una tiramira de cerros» que tenían una cierta continuidad; o bien un «lomo» destacado, que se prolongaba en el territorio. Hay que tener en cuenta, que la palabra cordillera deriva de cordilla - espinazo- - Sin embargo, nuestros conquistadores de América, y por similitud, lo magnificaron en Los Andes, que pasó a ser la Cordillera por excelencia. De ahí, que esta denominación lígrima del español sea la más pertinente para designar los grandes conjuntos montañosos, de modo indiferente a cuál sea su altitud. Es mucho más apropiado que el de sistema, que algunos geólogos alemanes a primeros del siglo XX dieron a la Cordillera Ibérica, que por su variedad más bien estratigráfica-litológica, y no por estar integrada por muy diferentes tipos de relieve, se avenía mal con sus ideas preconcebidas de otros conjuntos montañosos. Basta así con Cordillera Ibérica y Cordillera Central.

Una denominación, que también por inercia se ha mantenido de modo inexplicable por muchos geógrafos es el de La Meseta. Con antecedentes, fue consagrado por S. Calderón (1885) para designar el basamento paleozoico en torno al cual se han constituido los demás elementos del relieve de la Península Ibérica y que en el centro de España se encuentra a una altitud relativamente elevada. Pienso, que para dar expresión a la idea de A. Humboldt de un plateaux, que se elevaba en el Este y basculaba hacia el Oeste hasta hundirse en el Atlántico en Portugal. Esta última idea es otro tópico, que todavía pervive en la geografía española, ya que responde a la realidad de modo muy parcial.

Pase lo del plateaux de A. Humboldt que fue todo un descubrimiento; pero no así lo de La Meseta. La palabra mesa es un topónimo bastante frecuente en España para designar entre otros un cerro elevado de culminación plana, por similitud con el genuino de «mesa», aunque no siempre tenga el significado de un elemento del modelado. Por ejemplo, la Mesa de Ocaña, que se refiere a la «mesa magistral de la Orden de Santiago en La Mancha». Pero, el nombre de meseta es un diminutivo de mesa, muy extendido en el área mediterránea del Sur y Este. ¡Toda una contradicción con el significado macrogeográfico que se le dio hace ya más de siglo y medio!

Pero a lo desafortunado de su inserción en la geología, de donde pasó a la geografía, pronto se añadió su desvirtuación. Se le identificó con las llanuras de Castilla, y los escritores de la generación del 98, y aún anteriores, contribuyeron a su difusión. Hoy es la acepción más generalizada para la gente culta, e incluso sinónimo de Castilla. Nada tiene que extrañar, porque tenía una base en la percepción territorial. Los asturianos tradicionalmente cuando llegaban a León y los alicantinos a Albacete decían que habían subido a Castilla. En ambos casos se referían a sus llanuras. Hoy es frecuente, que señalen que han subido a La Meseta. Unos y otros hacen abstracción de las montañas que tienen que 
atravesar. Esta percepción de la llanura, que además son llanuras muy variadas, es fruto de una mala enseñanza de la geografía, que ha quedado muy influenciada por la literatura, y ha llegado hasta los geógrafos.

Pero además, esta sinonimia es en realidad un error; porque estructural y geográficamente son cuencas sedimentarias, rodeadas de conjuntos montañosos. Otro aspecto a confundir; más cuando en geografía se da carácter de generalidad a lo que es propio de estas llanuras (de estas cuencas sedimentarias) al conjunto de ambos elementos encuadrados en unas pseudoregiones históricas - hoy comunidades autónomas: son la Sub-meseta Norte y Submeseta Sur de los manuales, y muy caras a ciertos geógrafos.

Ahora bien, esta desvirtuación del concepto primitivo de La Meseta, como llanura e incluso identificándolo con Castilla, llevó a verdaderos contrasentidos. Este basamento paleozoico, que ha sido el núcleo en torno al que se ha formado el relieve peninsular, y que abarca las dos terceras partes de su territorio comprende grandes elementos estructural y geográficamente - regiones - muy dispares, que difícilmente se pueden encuadrar en lo que ha devenido el concepto de La Meseta. Así, para los gallegos, un conjunto muy diferente y que siempre ha diferenciado su región de la supuesta submeseta Norte, eran las montañas - las Galaico-leonesas, la «raya de Castilla»- que los separaban. Detrás de ellas empezaba «la planura, sempre planura» de la plañidera Rosalía de Castro. En la época decimonónica de los «regionalismos» si la exaltación de las llanuras como Castilla llevaba una carga ideológica, en estos otros, aunque todavía minoritaria, era la contraria. Había más que una antigua percepción; y los distingos eran muy patentes.

Sin embargo, en las primeras décadas del siglo XX los conocimientos científicos habían progresado, y La Meseta como basamento se había convertido en un concepto lábil, que había que corregir. Fueron entonces los geólogos, muy afines en su formación e ideología a sus antecesores de la centuria anterior, los que a La Meseta le dieron el nombre de macizo, y fue E. Hernández Pacheco el que acuñó la denominación de Macizo Hespérico. Bien lo de «macizo», porque el basamento o zócalo paleozoico en la Era Terciaria con la tectónica alpina fue fragmentado en grandes unidades con muy acusados desniveles; es lo que se conoce con toda propiedad como un «macizo antiguo». No así el calificativo de «hespérico», pues aparte de ser un cultismo rebuscado, es algo muy parcial, ya que sólo corresponde a un reducido sector de la Península Ibérica. Como tampoco es aceptable, que aun destacando las cuencas sedimentarias, a sus llanuras, que como mucho llegan a los $1.000-1.100 \mathrm{~m}-$, se les denominara altiplanicies. ¡Ni aunque estuviéramos en el Tíbet!. Hubiera bastado simplemente las expresiones «Macizo Ibérico» y las llanuras de «cuencas sedimentarias».

Ambos conceptos, aunque hayan sido acuñados por los geólogos, son enteramente asimilables por la geografía, puesto que corresponden a conceptos geográficos; incluso han quedado en su lenguaje. Hubiera bastado esto para que el de «meseta», enteramente inapropiado, hubiera quedado en el olvido o como una referencia histórica. Pero no ha sido así.

Mientras que los geólogos empleaban el del Macizo, aunque con el calificativo inadmisible de «hespérico», los más de los geógrafos siguieron apegados al de La Meseta, salvo excepciones, que hubieran acabado con imponer el de macizo. Sin embargo, fue otro geólogo en el ejercicio de geomorfólogo, y aun en el de geógrafo, el que contribuyó en los años sesenta a mantener el de meseta. No sé si por prejuicios de escuela o porque su origen era muy dado a lo tradicional, en un artículo que tuvo gran repercusión entre los geógrafos, de consuno con su gran y merecido prestigio le ha dado vida hasta nuestros días. Quedan así geógrafos meseteños y mesetarios. Parece que ha llegado el momento de alzaprimar, y adoptar el de Macizo Ibérico. 


\section{Conceptos erróneos}

Uno de los más difundidos es el de topografía que se emplea en la descriptiva para referirse al relieve e incluso al modelado. Sin embargo tal término corresponde a la representación en los mapas a desigualdades que representan el territorio mediante curvas de nivel con una escala 100.000/m.; y más generalmente mayor (1/50.000 y 1/25.000), y que por eso se denominan mapas topográficos. Son los que realizan los topógrafos con diversas técnicas y no los geógrafos; su objeto es reflejar la topografía. Son un medio imprescindible para estudiar el relieve o el modelado - lo verdaderamente geográfico-; pero de por sí no lo expresan.

Semejante uso, más bien abuso, de la palabra contrasta con su verdadera topofobia. Raros son los que mencionan las altitudes de los elementos. En el caso de geomorfólogos sólo los de las culminaciones; y para otros muchos geógrafos ni eso, la tierra es plana. Algo que se aviene muy bien con la palabra, que estuvo en boga hace unas décadas, y que aún persiste, la del espacio, concepto abstracto y polisémico. Indudablemente hay geógrafos que están en el «espacio», en el sideral, y ven la tierra desde un satélite que es su cabeza.

Pero el dislate llega al colmo, cuando se habla o se escribe de un territorio, que tiene una topografía muy movida. Yo ignoro, que aparte de los telúricos, haya movimientos continuos perceptibles. Hay otros vocablos en español, que expresan mejor las desigualdades y desniveles, que presenta el relieve o el modelado al que se refieren estos cantano geógrafos.

En relación con estas «confusiones topográficas» hay otras, que merecen ser destacadas. Una de ellas es denominar mapas a las representaciones cartográficas a escala superior a 1/10.000 m., tengan o no curvas de nivel. Estos son planos. Y no faltan los que se hacen un trabalenguas entre estos dos nombres; y a los mapas topográficos los denominan planos y a estos mapas. Me da por pensar, que es por tartaleo momentáneo de la mente, y no por ignorancia. Otra procede de esos geógrafos cuya única fuente de inspiración son los autores anglosajones, y cuando mencionan alguna altitud ponen entre paréntesis «s.n.m., sobre el nivel del mar», porque traducen height (s.n.). No se sabe si por desconocimiento entre altura - la diferencia en metros de un desnivel - y altitud, que se mide sobre el nivel del mar - en España se parte del cero en Alicante-, concepto que no es empleado en inglés, o es por pura pedantería. ¡Así para los incipientes es mucho más científico! ¡Qué duda cabe!

Muchas de estas desafortunadas palabras proceden de una época ya remota en el tiempo en el que todo aquello que se podía localizar en un mapa era geográfico. Se llegó a confundir lo uno con lo otro. De ello han quedado anacronismos que inducen a error. Así a los centros que confeccionaban mapas se les denominó «geográficos». En Francia fue el Institut Nationale de Géographie; en España por imitación simiesca el Instituto Geográfico $\underline{\text { Nacional. Resabio que aún perdura, puesto que se debería llamar Instituto Cartográfico }}$ Nacional, ya que los denominados «ingenieros geógrafos» y topógrafos lo que hacen son mapas de todas clases; pero no geografía. Ni es su misión ni tienen formación para ello. El nombre se ha mantenido por inercia y por intereses corporativos. Pero tampoco hay que darle mucha importancia; porque los arredros de la geografía de aquél tiempo pretérito son muchos.

Así ocurre con la palabra fisiografía, de cuño geológico, y coetánea de la «geomorfología», adoptadas ambas en EE.UU. el último quinquenio del siglo XIX. Esta última en manos de geólogos ponía todo su énfasis en los arrasamientos de distintas épocas de la historia de la tierra - penillanuras, superficies de erosión - que por medio de ellos trataban de buscar la evolución del relieve, aunque más bien era su formación, no cómo está en 
la actualidad. Para distinguirse de los otros geólogos, que se ocupaban con otros aspectos más propios de la geología, se proclamaron «geógrafos» (sic). En cambio el de fisiografía se empleaba por ellos, como descriptivo para encuadrar los hechos objeto de estudio, y como sinónimo de «geografía física».

Sin embargo, los geólogos más matreros en el conocimiento de las litofacies en relación con la estratigrafía en su cronología relativa, en su cartografía, así como en las puras estructuras geológicas, que no geográficas, eran poco avezados en el clima, vegetación e hidrografía, devalaban de la geografía física propiamente dicha, y la convertían en una verdadera morfografía, que tampoco llegaba a una geomorfología estructural. No pasaba de una visión geológica del territorio.

En España fue algo más de dos quinquenios después, cuando se difundió este concepto e igualmente por geólogos con síntesis fisiográficas y geológicas de las grandes unidades morfoestructurales del territorio ibérico. Fue un gran adelanto por insignes geólogos, que aún hoy hay que admirar. Pero adoleció del mismo defecto que el de sus colegas años antes del otro lado del Atlántico: replección geológica y mera morfografía. Y así ha quedado. Los geógrafos emplean la palabra, y no el concepto de un modo descriptivo, y con gran dosis de geologismo para referirse al relieve, y encuadrar las acciones erosivas y el modelado, que es donde ha acabado la geomorfología.

Esta es otra inercia antañona que ha durado ya más de un siglo, sin que los que la emplean hayan intentado averiguar cuál fue su origen, y hasta con cierto matiz despectivo para la geografía e incluso la geografía física; ya que adolecía de superficialidad, la misma que sigue teniendo actualmente. Entre estos últimos geógrafos «fisiográfos» no faltan los devotos del pensamiento geográfico, que no es naturalmente lo que han pensado ellos. Otros abocados a la historia de la geografía consideran como geógrafos de una «etapa naturalista» a estos geólogos que difundieron la palabra, y que fueron in partibus fidelium naturalistas.

Una expresión que en geografía también debe ser condenada al disparatario es la del medio ambiente, que hoy es la confusión de las confusiones. En parigual comenzó al otro lado del Atlántico, y se encetó por la contaminación atmosférica, el calentamiento global y el cambio climático. Los científicos expusieron sus teorías de un modo alarmista en el comedio del siglo pasado, y trascendieron como todo lo que tiene este sesgo a los medios de comunicación. Pronto surgió la mentalidad de que el planeta estaba en peligro. Naturalmente se produjo una reacción para defenderlo; algunos intelectuales por oportunismo o por creencia llegaron a lo ridículo y lo catastrófico con sus exageraciones; y dieron lugar a que apareciesen movimientos populares todavía más alharaquientos y hasta zaragateros (verdes y ecologistas). Ante esta situación, el gobierno federal tuvo que hacerse eco de esta nueva mentalidad, y pronto hizo que tomaba medidas más amidos que de buen grado. Aún tuvo más de propaganda que de efectividad no dejó de echar estiércol a la cizaña. Se convirtió en la preocupación de nuestra época.

Los diferentes especialistas se sintieron obligados a contribuir a resolver un problema que era vitando para la humanidad, aunque también hubo oportunismo. Fueron apareciendo así nuevos peligros: la desertización para algunas zonas del planeta, el agujero o agujeros de ozono, la desaparición de especies...La geografía no podía ser menos; era la que más se había ocupado del «medio», el environment. Pero cambiando el paradigma. Si hasta entonces había tenido el de la humanización del landscape - no es propiamente el paisaje - con la gran gesta de la construcción del territorio «americano»; ahora lo trucó por el deterioro que su sociedad le había infringido. El environment y el environmentalist pasaron a ser un nuevo paradigma, aunque no el único. Hubo geógrafos que publicaron tratados sólidos, mensurados y científicos. Pero esta preocupación por el medio físico fue 
de mucha mayor amplitud, y abarcó con sus teorías, problemas y debates a todos los países medianamente civilizados.

En España las nuevas ideas, con algún precedente en los biólogos, llegaron relativamente pronto. En 1970 se creó una asociación con este fin, en la que se mancornaron economistas, sociólogos, geógrafos, ecologistas, diletantes...Duró poco; pero sí tuvo trascendencia. A este jabardillo de gente heterogénea les pareció poco el medio, el medio físico, y aún el medio ecológico, y tradujeron el environment por medio ambiente. Expresión que por nueva tenía mucho de vetusta, pues en los años veinte del siglo XX, F. Cossio decía «en el siglo pasado la preocupación era el medio ambiente; ahora es el clima». España creo que es la única nación que al nuevo paradigma de abordar el medio le ha dado esta denominación.

Sin embargo, por desafortunada ha sido afortunada. En poco tiempo el medio ambiente se ha convertido en una verdadera balumba, en especial desde que se ha hecho oficial con un flamante ministerio, en el que en el saco entra todo, desde los temas habituales hasta los vertederos y la recogida de basuras. Así en cualquier municipio el concejal que se ocupa de esto, que se llamaba de «policía urbana», hoy lleva el pomposo nombre de «concejal de medio ambiente».

Aunque hay geógrafos que aún no se han enterado de este nuevo paradigma del medio físico, lo confunden con el «medio ambiente» e incluso esos geógrafos humanos, que lo han rechazado y nunca se han preocupado por su funcionamiento, tienen la avilantez de tratar «temas ambientales». Es más, para algunos el único sentido que tiene el medio físico en la geografía es como «problemas ambientales». ¡Todo un sarcasmo!. En su ignorancia marran más que los ecologistas. Claro que estos forman un movimiento para la acción, en el que no faltan actuaciones acertadas y meritorias; y aquellos no deja de caérseles de la boca, que son unos científicos.

Por eso, ante esta confusión el «medio ambiente» debe de quedar para esa jarcia de cuestiones inconexas; y la geografía mantener el de medio ecológico, que no físico, para la verdadera integración de su territorio. De ahí, que la traducción del environment que se hizo, me parece afortunada por desafortunada.

\section{De la jerigonza de la geografía física}

Es en este aspecto de la geografía en el que el lenguaje cae en lo esperpéntico, en especial en la geomorfología. Dos factores han influido en ello. La mayor parte de los geógrafos han estudiado en manuales extranjeros, en general mal traducidos; y los pocos manuales escritos por geógrafos españoles están inspirados en éstos o sus autores arrastran el lenguaje en el que se formaron. Por otro lado, por eso de que se trata de una de las «ciencias de la tierra», han entrado a saco en las expresiones de sus otros especialistas, lo que ha engarbullado más su lenguaje. Estos, como «verdaderos científicos» por lo general han estado muy alejados de la cultura, la contraponen a la «ciencia», la ignoran, cuando no la desprecian. De ahí, no sólo una verdadera logomaquia inteligible, sino una serie de voquibles, que deben ir igualmente al disparatario.

Uno de los más empleados es el de deposición para expresar el proceso de sedimentación o la formación de un depósito. Pues bien, en español deposición es principalmente «el movimiento peristáltico que realizan los intestinos para expeler los excrementos del cuerpo humano»; vulgo c... ¿Hay algo más grotesco? No sería más apropiado emplear para este concepto el término decantación. Algo análogo ocurre con los «conos de deyección» de los manuales franceses, que se sigue empleando; aunque por moda cada vez más se utilizan los «abanicos aluviales o torrenciales». Se piensa que las deposiciones o deyecciones están en escritos, que salen de la cabeza, que no del cerebro, de los geógrafos. 
La geología también nos ha legado otras gemas, que aparecen adunia en la geografía. Como el referirse al espesor de los estratos y capas se utiliza igualmente la de potencia. En muchos casos alternan ambas palabras; en otros más bien la última, que es completamente inapropiada. Pues en física potencia supone una energía o fuerza; algo que es por entero inaplicable a una litofacies. En relación con estas denominaciones estratigráficas está las de masiva al hacer referencias también a las litofacies que por su espesor y resistencia son siempre elementos de relevancia morfológica. Se trata de un galicismo poco apropiado. En español la palabra es únicamente un término médico, empleado cuando a un enfermo por ser necesario se le administra la dosis de un fármaco en cantidad muy superior a la habitual. ¿No sería mejor para estas litofacies darles el adjetivo de macizas o macizos en el caso de los estratos?

Más pintoresca es la expresión, que también se ha cogido de los geólogos de peni-

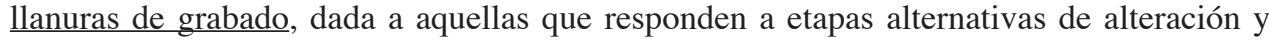
desmantelamiento. Deriva del verbo inglés to etch, cuyo sentido es grabar con un ácido. El darle un significado más amplio, el de corrosión, tiene mucho de metáfora; pero traducirlo por «grabado», porque el mencionado verbo en su traducción se parece al español, es todo un dislate. Ni se ajusta a la teoría por que se explican estas penillanuras, e introduce un sentido diferente. Se aprecia que estos autores saben tanto inglés como ignoran el español. ¡Pero tal facecia suma y sigue!

Una semejante es cuando por un calco del francés se recurre a la palabra incisión para señalar la acción erosiva que ha hendido en el territorio de modo más o menos enérgico y extenso. Pase porque incisión es toda hendidura poco profunda que se hace con un elemento cortante, pese a que no sea muy precisa; pero no cuando se pasa al adjetivo incidido aplicado al modelado. Parece derivar de incidir, «caer o incurrir en una falta» y sólo en medicina es hacer una incisión o cortadura. Pero como tal adjetivo no existe en español. Lo más parecido es incidente (lo que sobreviene en el curso de un negocio o asunto y que tiene alguna relación con éste) que tampoco se ajusta al resultado de la acción erosiva. Por eso carece de toda lógica utilizarlo en cualquiera de sus manifestaciones (encajamiento de ríos y barrancos o arroyamiento concentrado). Sin embargo, es muy empleado por un grupo de geógrafos con cierta afinidad.

Otro concepto, que se usa por otros también geógrafos, aunque de muy distinta librea es el de morfotectónica para señalar las unidades del relieve, que son el resultado de una tectónica de fractura, o simplemente para designar los grandes conjuntos morfoestructurales. En este sentido no es ni una corrupción del lenguaje, ni una traducción errónea, sino algo peor. El concepto fue acuñado por un afamado geólogo francés en los años sesenta del siglo XX para expresar la idea de un gran geógrafo, el primero que descubrió que en la elaboración de las formas del relieve iban a la par la construcción tectónica y la acción erosiva con influencias recíprocas. Por esta doble acción simultánea nació la palabra morfotectónica; de morfos, como procesos erosivos, lo que se atribuía como propio para los geógrafos - geomorfólogos - , que entonces aún se les designaba «morfólogos», y tectónica, lo que es exclusivo de los geólogos. Así la palabra, como concepto, se refiere a un tipo de evolución del relieve y no a sus formas tengan la dimensión que sea, e indiferente al tipo de fuerzas endógenas a las que se deban.

Semejante trapaza se comprende, porque afamados especialistas en determinados temas oyen palabras e incluso las leen; pero no tienen el sosiego necesario, sobre todo cuando son muy apegados a la grafomanía, ni tampoco la preocupación de enterarse de su verdadero sentido. Pero muy pagados de sus saberes las convierten en un comodín para designar lo que desconocen o con el prurito de la novedad. Puede que hasta se hayan enterado de su verdadero significado; pero aquí vale aquel principio de que «el principal procure acertarla bien / pero si la acierta mal / sostenella y no enmendalla». 
En su descargo está, que el geógrafo no pasó de esbozar estas ideas; y dedicó en casi su total y meritoria labor a la geomorfología climática; así como el geólogo que las perfeccionó su preocupación no ha sido precisamente el estudio del relieve, según su oficio. El que la geomorfología estructural haya quedado varada en sus primeros vagidos sin un desarrollo suficiente para el estudio del relieve, no sustituido por la tectonofísica, explica que el verdadero concepto de morfotectónica haya quedado casi omitido. Pero esto tampoco justifica el que se truque por lo que no es.

La consecuencia de haber estudiado la geomorfología por manuales extranjeros lleva a prescindir de palabras españolas, que son mucho más expresivas para designar conceptos que no pasan de localismos en otros países. Tal es el caso del galicismo de las «fuentes vauclusianas» en el modelado cárstico para designar las «exurgencias» en las que el agua hipogea sale a contrapendiente a gran profundidad. En español es a lo que se denomina alfaguara, palabra, además, de general, mucho más bella.

Igualmente origina el empleo de palabras que entre nosotros tienen otro significado o son inexistentes. Así se puede mencionar la de baqueta - del francés baquette- que se utiliza para cualquier rellano en el modelado al que no se le puede dar una interpretación. En España esta palabra es propia del lenguaje militar para designar una barra de acero inoxidable muy fina que se usaba, por lo menos antes, para limpiar el cañón del fusil. También hay el término vaqueta, que es un cuero de ternera pulido y adobado.

Algo análogo ocurre con otros dos neologismos que desde hace unas décadas se han introducido en la geografía física, y han pasado a toda la geografía. Uno de ellos es el hídrico para referirse a la circulación de las aguas lo mismo a las de escorrentía que a las fluviales; cuando siempre se ha hablado de hidrografía (del griego hidros) en un sentido general y descriptivo - la hidrografía de España-; o bien de hidrología en el caso de que se trate del conocimiento de su dinámica en el más amplio sentido, de sus causas e incluso de sus aprovechamientos reales, e incluso posibles, que originan cambios en los cursos de agua - Plan Hidrológico Nacional-. El otro es el antrópico para tratar cualquier acción humana que ejerza influencia en la vegetación o en el territorio, como la erosión antrópica. Palabra que expresa mal los conceptos a los que hace referencia. Más correcto sería emplear el término antropogénico; porque en ambos casos, como van demostrando los hechos y en especial en el primero, son de mucha mayor importancia, que una simple influencia, ya que esta acción humana puede generar una verdadera transustanciación.

Aunque el de «erosión antrópica» tiene más tradición que el «hídrico», es en las últimas décadas, cuando han adquirido un mayor uso, en especial entre los geógrafos moceriles, que parece que se les cae de continuo de la pluma, que no de la cabeza. Hacen lo que les han enseñado los pluscuangeógrafos para los que estas dos palabras parecían más «científicas». En vez de aclarar para los que no son geógrafos, lo que hacen es confundir; cuando lo que se pretende es dar difusión al valor de la geografía. Es una de las consecuencias que aqueja a muchos de estos últimos; y desde luego una corrupción de nuestro lenguaje, que tiene vocablos más conocidos.

Otro término que se ha colado de rondón en la llamada biogeografía, es el de plasticidad. Se emplea para expresar la adaptación de las especies vegetales a las más diversas condiciones ecológicas; y con más frecuencia a las que no responden al mecanismo ecológico, que es tan caro a sus especialistas, como aversión tienden a pensar en lo que dicen. Para expresar este concepto es por completo inadecuado. Plasticidad en español es la condición de plástico, que equivale a blando o dúctil. Se emplea para aquellos materiales naturales o artificiales, que con el agua o el calor se les moldea y se les da forma determinada. Es el caso de la cerámica, que dio origen a la palabra, o el de la «industria de plásticos» de 
derivados del petróleo, que la ha generalizado. Pero la palabra aplicada a la vegetación no sólo es incorrecta, sino también irracional.

Pues plasticidad es todo lo contrario a las especies vegetales, que en vez de blandas habría que calificarlas de duras por su capacidad de resistencia y de fuerza para pervivir, y aún para expandirse en muchos casos en condiciones aparentemente adversas. La plasticidad no está tanto en la vegetación, como en la mente de algunos confolonieros de la biogeografía, que la tienen tan dúctil, como ligereza en su lenguaje. Son los maestros; a los que siguen con fidelidad perruna los cantano geógrafos.

\section{Conceptos espurios y miméticos en geografía humana}

No es en la geografía física sólo en la que se machaca al español, y en donde el lenguaje se hace logogrífico, sino también en lo que se conoce como geografía humana. En lo que ha quedado de ésta, así como en la regional, se han introducido palabras bordes, que son verdaderos desafueros. Como ciencia social la una y la otra han entrado a saco en las otras ciencias también sociales, muy frecuentemente insociables - economía, sociología, y hasta en la ciencia política (sic) - . El vuelco hacia la geografía anglosajona no ha tenido menor importancia al respecto.

Ha habido una gran ligereza, cuando no ignorancia, al traducir palabras; y se hace con demasiada frecuencia hablar el español en inglés, en vez de ser al revés. No se trata de nuevos conceptos, aunque no falten, sino de algunos muy viejos en geografía. Palabras hay en nuestro lenguaje que las expresan mejor.

Empezaré por uno que ahora está haciendo época: la de asentamientos para referirse a la distribución y características de las entidades de población. Es una traducción directa de la palabra settlements, que ha venido a sustituir a la castiza de poblamiento, cuyo significado es la acción de ocupar un terreno para habitar. Y naturalmente para esto es imprescindible construir edificios para morar y para las actividades que lleva consigo vivir. En España con este significado, enteramente geográfico, se empleó en los años sesenta del siglo XX para superar la desafortunada de hábitat, que era utilizada por los geógrafos franceses, muy alejado del étimo significado que le dio mucho antes su creador.

Corresponde al primer cuarto del siglo pasado, cuando el ruralismo era lo substancial de la geografía; y éste se encontraba encuadrado en el determinismo y en lo etnográfico. En este último aspecto, una preocupación era «la casa del campesino» como morada y taller en sus variedades y los tipos de poblamiento, concentrado o disperso según las disponibilidades de agua en el territorio, era cuestión de regiones húmedas, abundantes en ella, o secas en las que surgía en contados lugares. Semejante simplicidad pronto dejó de ser un tema atrayente y fue sustituida por la geografía agraria. Sin embargo, en España no faltan geógrafos que sigan empleando la palabra hábitat con este significado; y alguno de esos de la historia de la geografía, o más bien de los geógrafos que nunca han sido, que ayuno de historia, lo haya resucitado recientemente y de modo paralelo del hábitat rural.

Pero es la excepción; lo general es que se haya trucado por los settlements con la traducción más genérica, la de «asentamientos» de modo impreciso y con diferente interpretación; pero haciendo caso omiso de lo que en realidad se refiere al poblamiento, la expresión settlements of lands, que equivale a «colonización». Y en efecto es a ésta a la que corresponde los tipos y variedades tradicionales. En España su riqueza es grande en relación con la repoblación-colonización medieval, no sólo con sus diversas etapas, sino también por las directrices que señaló el poder en los diferentes reinos hispánicos. Crearon una estructura que todavía pervive, lo mismo en las áreas rurales, que en las ciudades, que 
por ser también una forma de ocupación del terreno, son igualmente una clase de poblamiento, el poblamiento urbano.

Sin embargo, este aspecto constituye una laguna en la geografía española. Su desarrollo tardío a partir de la década del cincuenta del siglo XX, cuando todo se centraba en la geografía agraria, hizo que se dedicase poco o ninguna atención. Posteriormente han surgido otros tipos de poblamiento (turístico, de vacaciones, de ocio, polígonos industriales); pero se ha seguido la misma tendencia de omitirlos en su verdadera realidad. Si para los tipos y clases de poblamiento del pasado no se ha recurrido a una investigación geográfica e histórica, ni a la transformación que han experimentado, a los de la actualidad se les ha dado un tratamiento económico o sociológico en una geografía del comportamiento. Pero se desconocen sus diferentes tipos, y hasta su significado en el territorio. Se mancornan unos con otros, y aparecen bajo el concepto difuso de lo urbano.

Semejante ausencia ha relegado al olvido la palabra poblamiento para las nuevas generaciones, más dados a remedar, que no a interpretar el calco del concepto inglés de settlements. En su descargo está la falta de atención que se ha dedicado al tema. Ante un hecho tan visible, que deja su impronta sobre el territorio, se han asido, y con poca reflexión a lo que han encontrado sin ningún espíritu crítico; y sobre todo despreciando lo poco que se había hecho por los geógrafos de las dos generaciones anteriores. Es lo nuevo; y lo nuevo no siempre es lo más aceptable; porque muy frecuentemente tiene mucho de viejo.

Lo que tiene menos disculpa es que geógrafos de una generación intermedia, que han conocido lo que significaba la palabra «poblamiento», incluso la han escrito, hayan adoptado por un prurito de estar al día la de «asentamientos», y de manera chirle, para hacer referencia al número de habitantes de las entidades oficiales cuando además por su morfología y distribución es un tipo de doblamiento en cuanto a su origen sumamente interesante. Esto es cambiar los ojos por el rabo, como se dice del topo. Una clase, como otra cualquiera, de pedantería. Lo peor es que así confunden a sus discípulos, y los convierten en insipientes.

Otro tanto ocurre como otro calco, que no traducción del inglés, de la expresión land use, «usos del suelo». ¿Es el suelo, el territorio o el terreno? Si se trata del suelo urbano, serán solares, repajos o campos abandonados - suelo urbanizable-. Si es por el contrario, el «suelo agrícola» se entra en otro concepto muy distinto. Pero en cualquier caso el suelo no se usa, sino que tiene un aprovechamiento, una explotación, que lleva consigo una rentabilidad, sea agrícola o urbana, que se convierte en un valor inmobiliario. Es algo permanente; y no una cosa que se usa, como la ropa, el calzado, que cuando se estropea sin remisión se tira, como el papel de envolver y sobre todo el higiénico, que usado se va por la cañería. Es una expresión tan generalizada, como garrafal. Pero sobre todo un modo de bastardear nuestro idioma. Es otra medalla, que al igual que algunos especialistas de otras ciencias (sic), también pueden colgarse los geógrafos.

En otros casos es la adopción de conceptos de otras ciencias, o bien de la jerga administrativa. De esta última, se ha tomado eso de la S.A.U. (Superficie agraria útil). Es un concepto innecesario; y además una renuncia a lo geográfico por el recurso fácil a las estadísticas oficiales, que por regla general tienen mucho de falseamiento de la realidad. En España décadas atrás se habían acuñado palabras que lo expresaban mejor. Una de esas era la de terrazgo de gran abolorio en castellano, en el que se incluían además de los huertos, los prados, que son igualmente un modo de cultivo. Estos elementos se diferenciaban de los montes, que englobaba todo lo que no era cultivado. Aunque, exceptuamos algunos casos, poca atención se dedicaba a sus diferentes aspectos en el significado que tenían, y aun conservan, en la economía rural de muchas regiones. Bastaba alguna referencia a ellos; pero no cómo se realizaba su aprovechamiento. 
Hoy lo agrario ha sido sustituido acertadamente por lo rural; pero con la SAU sigue siendo más lo primero que lo segundo. Y todo énfasis se pone en la producción, y en los problemas, que en los momentos actuales, enfrenta. No hay por qué rechazarlo; pero no darle carácter de exclusividad. Pues con este economicismo se hace abstracción de los elementos de que consta esta economía rural, y que tienen clara manifestación en el territorio. Se da cuenca de lo que hay en éste; pero no de cómo está en él. Parece que la geografía ha dimitido de lo que es su objeto; dar imagen y explicar lo que se encuentra sobre la superficie terrestre; y cómo afecta al grupo social que en ella vive.

Se justifica el empleo de estos datos de la SAU, al igual que otros oficiales - los de los Censos Agrarios - porque son los únicos que hay para dar una expresión cuantitativa a lo cualitativo. Esto es algo innecesario; pero invirtiendo los términos. Estas estadísticas están plagadas de errores por el modo que tienen de confeccionarse; es algo que todos somos conscientes. Por eso todo lo más su valor es indicativo; pero no se les puede elevar a la categoría de dogmas, como se está haciendo, y se ha hecho desde hace tiempo. Entonces también por ausencia de otros se tomaban los provinciales. Son esas geografías de provincias, que por desgracia siguen reiterándose, en las que se hace un todo de lo que son partes; pues rara es lo que es homogénea; ya que las más constan con comarcas, e incluso forman parte de regiones muy distintas. Ha sido una constante, que se ha repetido con exceso, y desde hace mucho tiempo. Pero en esto se sigue el viejo y nefasto principio, el de «sostenella y no enmendalla».

La obsesión por la estadística lleva muy frecuentemente a devalar de la realidad, cuando bastan algunos datos obtenidos por encuestas hechas con paciencia, continuidad y rigor para expresar lo cualititativo, que tiene carácter de generalidad. Naturalmente esto exige tiempo, perspicacia y contacto bastante perseverante con la realidad. Por eso, sobre todo en esta época de «curriculus» es mucho más hacedero y rentable desde un despacho utilizar las estadísticas oficiales, cruzar los datos en el ordenador, y los resultados son los que sean. Así resultan esos artículos y hasta libros tan ahítos de cifras y tantos por ciento como vacuos de ideas. Tal repleción de aquellos como ausencia de éstas los hace ininteligibles y confundentes. Por eso, no hay nada más peligroso que uno de esos galeotes de los «papers» con un ordenador y estadísticas oficiales. Es uno de los modos, si no unos malos modos, de acumular méritos inméritos para progresar en el currículo; pero no para hacer una geografía que tenga trascendencia, como «ciencia social» para la sociedad.

Otra joya que la geografía ha adquirido de segunda mano es la de organización del territorio. Cuando los geógrafos españoles habían condenado al disparatorio la región, y sin que hubiese razón alguna para ello, y llevaban discutiendo más de una década, si la geografía tenía que ser de galgos o podencos, surgió al margen de ella una ciencia territorial. Fue una invención de los economistas, que tarde cayeron en el territorio con ensayos verdaderamente desafortunados; y por técnicos que tenían que actuar sobre él. Era un instrumento para la planificación ante las transformaciones que se habían producido. Ante la ausencia de unos conocimientos necesarios para esta actuación con un adanismo sorprendente descubrieron otro modo de «conocimiento». Los diagnósticos fueron superficiales; y la terapeútica con errores garrafales. Como ciencia ( $\mathrm{sic}$ ) ha creado más una logomaquia, que un conjunto de ideas coherentes. Les faltaba un arma de la que carecían: la que le hubiera proporcionado una geografía regional perfeccionada; precisamente la que habían desechado los propios geógrafos.

Éstos tardaron en darse cuenta en sus discusiones estériles; y cuando se percataron, ya era un tren que circulaba, trataron de cogerlo en marcha. Había que volver a la región para lo que estaban ya mal preparados por su abandono. No obstante tarde y mal lo hicieron. Pero también con una nueva invención: la de análisis regional y organización del territorio. 
Todo un dislate geográfico. Vergonzantes de su oficio la región quedó truncada por lo de análisis; y no conocimiento integral de los elementos geográficos. Aunque también en esto debió de influir ese principio, que ha señalado, anteriormente, el de «no enmendalla»; y tomaron lo de organización por reorganización, renunciando a lo que era su cometido.

Porque el territorio está ordenando; en él siempre hay un orden, aunque parezca un desorden; esto es precisamente lo que hay que averiguar, porqué y para quien. Es lo que tenía que haber estudiado la geografía regional; y en trance de ello estaba, cuando se lanzó por la borda. Este era el verdadero diagnóstico, que se podría haber proporcionado. Pero con el tiempo y con especialismos cómodos habían perdido capacidad de hacerlo los más de los geógrafos. Sin embargo, tampoco hay que exagerar. No faltaron los que por convicción se mantuvieron fieles a la geografía regional clásica, que no anticuada, y, han podido contribuir de un modo eficiente afesta reorganización del territorio. Por sus obras los conoceréis.

Otros han vuelto a la región; pero bajo prejuicios ideológicos enmascarados en su incapacidad, y con fines poco geográficos a somormujo. Hay así varios conceptos de región, todos tan inéditos como inoperantes. Lo que tienen en común, es que han renunciado a la infraestructura ecológica. Son regiones de ese concepto polisémico y ambiguo del espacio, que lo mismo está en el cosmos que en el firmamento; es decir, que en geografía es un ente de razón sin razonar. Cierto es que las especializaciones han dado profesionalidad a muchos geógrafos; pero más como gregarios de los verdaderos «organizadores-reorganizadores». ¡No deja de ser un consuelo! Aunque tampoco le ha conferido a la geografía el prestigio, que tuvo en un otraño ya lejano; y quizá afortunadamente. Algunos geógrafos aquejados del virus de la rabia, en su radicalidad, es la geografía que se hizo para hacer la guerra por haber buscado la paz.

Convertida la geografía después de la «revolución geográfica» de los años noventa en una baraja de muchos naipes, todos ellos muy científicos, se han colado en ella muchos ases de bastos, que no de oros; y también, aunque menos, de espadas. Los geógrafos, los han cogido con albricias y hasta con alharacas; pero han truncado lo suyo por lo de otros. Veamos algunos de estos naipes.

En su tiempo había desde el punto de vista académico una geografía de la población, en la que se estudiaba la distribución de la población, y los mecanismos biológicos, económicos y sociales que condicionaban a escala mundial su evolución. Hubo obras que aún entran en lo clásico. Era la explicación sencilla de lo complejo; pero muy eficiente. Proporcionaba un conocimiento muy enjundioso no sólo de la población, sino también de sus problemas sociales y económicos, y hasta de eso, que hoy está tan de moda, «las culturas».

En cambio, ya desde hace más de una década se ha tornado en demografía pura y dura, en la que se sigue miméticamente los conceptos y métodos de demógrafos y sociólogos. Pero en realidad es cada vez más un conjunto de índices y tantos por ciento sin una clara relación y sopesada idea con el contacto con los distintos territorios a los que se refiere. La verdadera interpretación brilla por su ausencia; si no es mediante los tópicos heñidos de lo que se sabe por el conocimiento convencional. Es decir, por ese sentido común, que es una fuente de errores. Se comprende porque la evaluación se hace a escala muy general por estados o por grandes regiones político administrativas con poco distingos cualitativos, ya que no se ponen en relación los datos estadísticos con el verdadero contexto de la realidad. Pero con estos datos y un ordenador es otro medio de hacer publicaciones indigestas; pero muy curriculares. ¡Todo un éxito!

Y en relación con esta elisión de la geografía está otra no menos difundida: la de recursos humanos. Es algo tomado de prestado, y a la ligera de la llamada ciencia económica. Hoy aparece en lo que antes se denomina oficina de personal desde los centros oficiales hasta los hospitales pasando por las más variadas empresas. Aquí puede tener sentido, porque se 
evalúan funcionarios y empleados por su distinta cualificación para los fines de estos organismos. Pero en geografía en la que también ha entrado a saco, puede no ser lo mismo.

Así hay geógrafos, que en estudios sobre áreas rurales con una población enteramente envejecida aplican al capítulo correspondiente esta expresión de acarreo. Se piensa, si es un recurso o un problema. Pero, además, para los pocos que mantienen una actividad, hay poca precisión para demostrar de que modo son un recurso. Sólo se recurre al grado de estudios, que es lo que se puede obtener de las estadísticas oficiales, y esto para toda la población; pero no para éstos que acabo de mencionar. En ellos se hace caso omiso de sus conocimientos técnicos sobre las máquinas y modo de cultivar o criar el ganado, hoy muy diferentes de tan sólo unas décadas; de sus sistemas de información sobre precios de cosecha o de aperos, y de comercialización, así como de mercados; al igual que del modo de llevar la contabilidad del producto bruto y neto, que determina su nivel de vida - lo verdaderamente social - y de capitalización; y también de sus ideas de innovación para defenderse de los retos a los que se enfrenta hoy la actividad agraria. En la actualidad no hay campesinos; estas gentes se denominan a si mismo agricultores, ganaderos cuando no «empresarios», entre los que no faltan técnicos de grado medio, y aún superior, que practican esta actividad. Y a éstos sí que se les puede considerar como un recurso humano por el valor que tienen en una economía regional o nacional.

Naturalmente nada de esto figura en las estadísticas; y por tanto, no existe para los geógrafos de despacho; solo se consigue con encuestas muy afinadas y pacientes. Pero esto no es rentable. Afortunadamente hay geógrafos, que más que fijarse en esto, pretenden, y consiguen explicar todo lo referente a esta nueva actividad; y si tienen en cuenta todos estos aspectos. Pero por desgracia son pocos.

Ahora bien, saliendo de España, y al abordar los estados del llamado Tercer Mundo (sic), esas masas humanas en la pobreza, si no en la miseria, que son la verdadera «legión famélica». ¿Se les puede aplicar la expresión de recursos humanos? ¡Cómo no sea para las pateras....! Aquí más bien son un problema; y por paradoja en estados que a veces tienen muchos recursos. Claro está, que salvo los tópicos de los geógrafos radicales, se desconoce todo. Se debe a esa geografía regional, incriminada de descriptiva, y que se considera una antigualla. Es el caso de la zorra: no están maduras. Resulta, que ya la geografía no sirve para conocer el mundo. ¿Lo conocen los geógrafos? Esos mismos que se reían de aquél que no sabía donde estaba Afganistán, y que eran tan ignaros cómo él. Pero la geografía es una ciencia social imprescindible para transformar la sociedad ¿No será mejor conocer lo que es propio de ella? Cómo es la superficie terrestre.

Pero de la perla, que se ha apropiado la geografía, la de mayor valor es esa de que el espacio es un producto social. Vayamos por partes. ¿Qué espacio?. No el sideral, sino el de la Tierra. Una abstracción entre las abstracciones. Porque prescinde de lo que es la superficie terrestre con su configuración variada en todos los aspectos, que es lo geográfico. El espacio es todo; lo que equivale a nada. Lo fácil, que se utilizó - y entonó la palinodía - para superar «el paisaje formalista», cuando éste no daba más de sí. Fue otro error y otro término desafortunado. Cada época tiene sus palabras, su locura, como cada hombre tiene su cara. Hoy el territorio se aviene mejor con la superficie terrestre, ya que indica una parte concreta de ella.

En cuanto al producto social hay que precisar, que es una vieja idea del marxismo, a la que ya M. de Unamuno calificó de mentira. Fue revivida con la de espacio por el filósofo H. Lefèvre (1974). Hizo época en el periodo en el que impregnó este sarampión a los intelectuales de entonces. En España corrió como la pólvora ardiendo; y aún a muchos les sale adunia de la pluma, que no de la cabeza. A unos por vieja afinidad ideológica; y a otros 
porque lo repiten, como si fueran loros. No le daré el duro calificativo, que he mencionado antes; pero sí considero, que es inapropiado geográficamente.

Producir, es crear, elaborar, fabricar o construir algo nuevo a partir de diversos materiales; y producto es el resultado de esta acción. La sociedad, o más bien los que la dirigen o manipulan, pueden transformar, modificar el territorio, el espacio si se quiere, pero nunca crearlo o fabricarlo. Como metáfora puede pasar; pero en geografía tales metáforas sobran. Es otra expresión, que por pertenecer al pensamiento ha sido poco pensada; y por paradoja en la época del pensamiento geográfico. Está de más; hoy a ningún geógrafo se le ocurre poner en duda, que la superficie terrestre, salvo los anecumenes, está humanizada. Es un axioma que está implícito en la geografía; e incluso el territorio hace referencia a ello.

Por eso, semejante expresión merece también ir más al disparatorio, que muchos otros conceptos, que a éste se condenaron.

\section{Del lenguaje convencional a lo esperpéntico}

Pero no sólo es la geografía la que se ha contagiado del mal en sus conceptos, sino que igualmente los geógrafos han sido infectados por el virus de las mañas o malas mañas de los medios de comunicación y de los políticos, entre otros. Es una gargantilla de múltiples cuentas, que tanto produce asombro, como hilaridad; sin que falte tampoco la pedantería de la incultura de los cultos; y la insipiencia de los geógrafos moceriles, que esparcen palabras a voleo como chorlitos.

Algunos - ¡como no! - pertenecen al spanglish. Tal es el caso, cuando se emplea implementación (de to implement) por llevar a cabo, ejecutar o realizar algo. ¿Es que se piensa en inglés por no pensar? De monitorización (de to monitor > controlar un programa. Acep.) por controlar o hacer el seguimiento de algo. Se piensa que los apegados a tal voquible deberían «monitorizar» su pluma o su lengua. ¡Y que decir de esponsorización o esponsor por patrocinar o por patrocinador! Tendrían que buscarse un padrino que les enseñase de nuevo a hablar español.

Pero también hay palabras, que con igual ligereza derivan del francés e igualmente devalan de nuestro idioma. Quizá la más usada es la de remarcar (de remarquer $>$ observar, notar) por resaltar, cuando en español es volver a marcar. Otra que todavía utilizan algunos geógrafos es la de irrigación o campos irrigados por regadío. En nuestro idioma es un término médico (rociar, regar con un líquido alguna parte del cuerpo) y la acción y efecto de irrigar. La «irrigación» en el más extendido de los significados era realizar esta acción como una «lavativa». ¡Ay eso de traducir literalmente!

Otros de estas perlas del collar provienen de la desvirtuación de la palabra española. Tal es el caso de geógrafos hechos y derechos, que hablan de la personalización de la región. No deja de ser un contrasentido; porque personalidad se refiere a las «personas» o a los rasgos individuales. Por lo que no es aplicable al territorio, que si tiene características; y los hombres que viven en una región y con el tiempo la han marcado con su impronta lo que tiene de común entre unas y otras es muy poco. ¿No se está confundiendo personalidad con singularidad? Claro que ahora, cuando la geografía ha pasado a ser la ciencia de los hombres sobre el espacio, y no los hombres en sus relaciones con el territorio, a lo mejor tiene un significado para algunos, que a otros muchos más lerdos se nos escapa. No acabo de comprender si somos nosotros o ellos los que tenemos que volver a aprender los primeros vagidos del lenguaje.

Quizá ocurra lo mismo, cuando se señala de alguna idea o hecho que tiene trascendencia o que produce asombro, que es impactante o que impacta. Pues deriva de impacto, «el choque de la bala con el blanco o la huella que deja este choque». Claro que hay tantos 
choques y de todo tipo, que no importa uno más. También hay palabras, que de por sí indican una acción, como conectar o accesible y se las transforma en «conectividad» y «accesibilidad», lo que no deja de ser una redundancia. Al igual que otra también muy difundida es la de particularidades identitarias; pues todo lo que es particular identifica; pero, además, el reiterativo identitario es difícil saber a que idioma pertenece. Desde luego al chino no; pero tampoco al español. ¡Y que decir de esa expresión de nuevas reconfiguraciones! ¿Reconfigurar no supone ya una nueva configuración?

Pero tampoco hay que perder de vista a esos pluscuamgeógrafos, que utilizan conceptos filosóficos de modo trivial, y con un significado diferente al que los acuñó, como reconstrucción, especificidad o alteridad entre otros. Son los cultos a la violeta; pura pedantería. No aclaran y sí confunden. ¡Y esto en la etapa de la geografía cultural! ¿No será más bien al contrario? 